\title{
Medical rehabilitation
}

\author{
Christine Collin
}

Medical rehabilitation in 2011 and beyond is the fourth report by the Royal College of Physicians (RCP) to focus on rehabilitation medicine (RM) and is in sharp contrast to its predecessors, with a clear focus on communicating with commissioners. ${ }^{1}$ It defines the specialist roles of RM physicians in rehabilitation services and provides recommendations supporting the provision of high quality, accessible specialist services according to need and in line with the National Service Framework's (NSF's) recommendations for long-term conditions. ${ }^{2}$ It promotes the rights of individuals with a disabling disorder to have timely access to specialist rehabilitation expertise to allow them to live their preferred lifestyle.

While recognising the 'diagnose, treat, discharge' philosophy of modern clinical management, which has focused sharply on reducing the costly use of secondary care acute hospital beds, this report points out clearly, and with evidence, why the clinical pathways of disabling disorders require lengthy or repeated access to RM specialists and their services. Figure 1 illustrates the provision of RM specialist services in hospital and in the community, and how they fit into the matrix of other services. The pathways also identify the few people with highly complex needs, eg those in a minimally aware state, who may require access to a specialised regional or supraregional service for a period of treatment before returning to their local resources for longer-term management.

It highlights the need, captured in the current initiatives on stroke care, critical illness rehabilitation and trauma care networks, for early high intensity specialist rehabilitation intervention, but also emphasises the necessity for excellence in downstream specialist RM services, wherever they are situated, to continue the work begun in the acute stages. Great flexibility in the commissioning process will be needed to support integrated, personalised and complex packages of interventions. Commissioners will also need expert advice as the specialty developments encompass high-tech equipment, new neuroprotective drugs and novel treatments.

Some of the generic pathways developed for specific conditions like stroke are excellent in their attention to rapid diagnosis and early treatment and for the overall upgrading of community-based service provision after early discharge from hospital. They fail to capture the need for some stroke survivors to have access to a specialist rehabilitation service with high intensity treatments, sometimes for many weeks, to support them in their need to return to their old life. There may, in addition, be specific vocational needs to address. Some people with

Christine Collin, consultant physician, neurorehabilitation medicine complex cognitive needs and disability due to stroke do not fit the early supported discharge package of care.

The document is also in sharp contrast with its predecessors in that it has a deliberately low carbon footprint with online access to the full document via the RCP website initially, and a small production by the British Society of Rehabilitation Medicine (BSRM, the joint sponsor of the report) of printed copies. It has been produced at a time of great change. There are huge worries concerning the uncertainty of the likely impact of financial cutbacks in the public sector which could dramatically influence commissioning and the provision of specialist services. There will be an early review of this document after the new commissioning arrangements announced in the coalition government's White Paper have been embedded into the NHS. ${ }^{3}$

In 2009, the third edition of the National Definition Set for specialised services was published and, for the first time, included definitions for RM services. ${ }^{4}$ It was recognised that there was huge overlap in the definitions of highly specialised and specialised RM services. The Department of Health (DH) requirement that only units serving a defined population base of a million or more could be eligible for the highest tariff for highly specialised rehabilitation was seen as dogmatic. It did not reflect current practice in which many RM units at any one time will be treating a number of patients with highly complex needs and a number with less complex needs. In the longer term, this development of the definition sets should lead to clarification of need, complexity and needs-based commissioning, rather than imposing set tariffs for different units, which would disadvantage services in some areas of the country.

The Darzi Report, High quality care for all, has influenced the shape of future health services and has championed the provision of services closer to home, recognising that many, including some specialist ones, could be provided closer to, if not in, people's homes to reduce pressures on costly hospital-based services. ${ }^{5}$ This will be possible for some services and health activities but not for all and is likely to simply add to the rich variety and diversity of health service provision in the UK as innovations continue on a local, rather than national, basis. The coalition government's White Paper detailing changes in commissioning structures will also influence service provision. ${ }^{3}$

The BSRM has contributed to the development of standards of practice in a variety of settings. ${ }^{6,7}$ Appendix 1 of the report describes in detail the requirements for a high-quality service and will assist in the design of services and job planning. Goal setting and outcome monitoring have become standard practice for inpatient-based rehabilitation but have not yet become a standard component of outpatient practice. The United Kingdom Rehabilitation Outcomes project (UKROC), funded by the $\mathrm{DH}$, is 


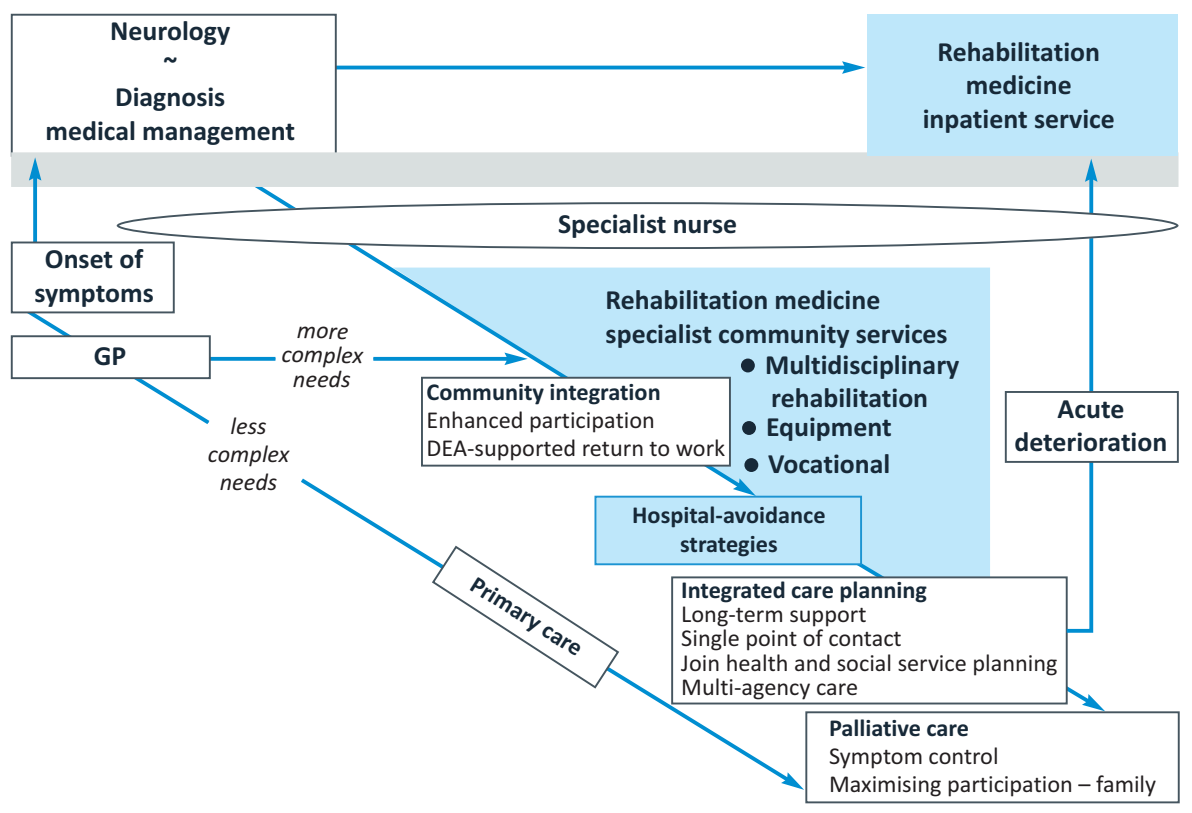

Fig 1. Example of a clinical pathway that demonstrates the complexity and variety of options for an individual with a long-term neurological disability. DEA = disability employment adviser. Reproduced from reference 1.

a collaboration between BSRM and the NHS Information Centre which mandates the collection of specific outcome measures to provide information on case-mix, rehabilitation needs and rehabilitation interventions. These data were being collected voluntarily at inception but are likely to become a requirement for commissioning of specialist rehabilitation services. The National Dataset is described in detail in Appendix 2. Long-term collection of such data will require specific funding. Though UKROC initially focused on describing and qualifying the high-cost specialised rehabilitation services that are often found in regional or supraregional hospital-based centres, ultimately all services, wherever they are based, in the community or in a teaching hospital, can be described, detailed and costed by its methods.

The chapter on the synthesis of the evidence of benefit of skilled specialist rehabilitation interventions is a key part of the report based on the Cochrane reviews of randomised controlled trials and the evaluation of qualitative evidence and mixed method studies used for the production of the NSF for long-term conditions. ${ }^{2}$ A further systematic review was beyond the scope or timescale allowed for this piece of work. The quest for evidence of benefit and cost effectiveness must continue, to support developing practices and novel interventions. The strength of evidence that is available now should prevent a nihilistic response from commissioners when asked for support for our services.

Commissioners will require clear advice on commissioning specialist rehabilitation services for local populations. Rehabilitation medicine physicians can provide evidence of the benefits to individuals of the expertise of specialist RM team interventions, and they can promote highly effective programmes of intervention, whether based in traditional hospital centres or elsewhere. There is a drawback to the expected decanting of services into the community which has not been well considered and merits serious attention. The ability of any individual physician to work effectively in a variety of locations and with a number of teams is beyond doubt, but is likely to reduce productivity. Remaining competent and at the cutting edge of one's specialty often requires a critical mass of experience and contact with other likeminded specialists. This will take greater effort for those people working in more isolated community placements than for those working in regional centres. Flexible working patterns and job plans reflecting these observations will be needed and the specialty will require significant expansion if the services available to those people in the UK with long-term neurological disability are not to fall far behind those available in most of the developed world.

The specialty of RM manages complex and expensive conditions, and is likely to change markedly over the next few years. Proactive, integrated and timely specialist rehabilitation can significantly reduce the impact of disability and prevent complications. This report provides an excellent starting point for all who are concerned with maintaining the best of current practice and commissioning and developing specialist rehabilitation networks to meet the future needs of their local population.

\section{References}

1 Royal College of Physicians. Medical rehabilitation in 2011 and beyond. Report of a working party. London: RCP, 2010.

2 Department of Health. The National Service Framework for Long Term Conditions. London: DH, 2005.

3 Department of Health. Equity and excellence: liberating the NHS. London: DH, 2010.

4 Department of Health. Specialised services national definition set, 3rd edn. London: DH, 2009.

5 Darzi AW. High quality care for all: NHS next stage review final report. London: DH, 2008.

6 Turner-Stokes L, Williams H, Abraham, Duckett S. Clinical standards for in patient rehabilitation services in the UK. Clin Rehabil 2000;14:468-80.

7 Turner-Stokes L, Williams H, Abraham R. Clinical standards for specialist community rehabilitation services in the UK. Clin Rehabil 2001;15:611-23.

Address for correspondence: Dr C Collin, c/o Royal Berkshire Hospital, London Road, Reading RG1 5AN.

Email: christine.collin@googlemail.com 